\title{
FRICTION MEASUREMENT IN MEMS USING A NEW TEST STRUCTURE
}

B.T. Crozier ${ }^{a}$, M.P. de Boer ${ }^{b}$, J.M. Redmond ${ }^{b}$, D.F. Bahr ${ }^{a}$, and T.A. Michalske ${ }^{b}$

${ }^{a}$ Mechanical and Materials Engineering, Washington State University, Pullman, WA 99164

${ }^{\mathrm{b}}$ Sandia National Laboratories, Albuquerque, NM 87111

ABSTRACT

A MEMS test structure capable of measuring friction between polysilicon surfaces under a variety of test conditions has been refined from previous designs. The device is applied here to measuring friction coefficients of polysilicon surfaces under different environmental, loading, and surface conditions. Two methods for qualitatively comparing friction coefficients $(\mu)$ using the device are presented. Samples that have been coated with a self-assembled monolayer of the lubricating film perfluorinated-decyltrichlorosilane (PFTS) have a coefficient of friction that is approximately one-half that of samples dried using super-critical $\mathrm{CO}_{2}\left(\mathrm{SCCO}_{2}\right)$ drying. Qualitative results indicate that $\mu$ is independent of normal pressure. Wear is shown to increase $\mu$ for both supercritically dried samples and PFTS coated samples, though the mechanisms appear to be different. Super critically dried surfaces appear to degrade continuously with increased wear cycles, while PFTS coated samples reach a steady state friction value after about $10^{4}$ cycles.

\section{INTRODUCTION}

Adhesion [1-3], friction [4-6], and frictional wear [7-9] represent important failure mechanisms in MEMS but have not been extensively characterized. An improved knowledge of surface interactions, frictional forces, and lubricating coatings will help to improve the lifetime and reliability of MEMS devices that have rubbing surfaces. A variety of methods for evaluating interfacial friction and coating performance exist, with each method having distinct advantages and disadvantages. MEMS reciprocating comb driven friction devices [5-7] have proven useful. The surface roughness, coatings, and environmental history of the device are representative of adjacent, functional micro systems on the same chip. Also, the mechanics analysis to measure friction is straightforward. However, their relatively large area consumption on a wafer limits their potential use as on-chip surface diagnostic devices. Furthermore, the small force provided by comb drives limits the range over which pressure can be measured to about one order of magnitude. With such devices, several methods for reducing friction and wear have been explored, with a large effort directed at the application of low surface energy coatings, in particular silane monolayers [5,8]. Investigators employing electrostatic comb-driven friction devices have reported sliding friction coefficients around 0.4-0.5 [6] for polysilicon surfaces with a hydrophilic oxide. Static friction coefficients have been reported between 2 [5] and 5 [10] for supercritically dried, oxide coated surfaces, and as low as 0.1 for surfaces coated with hydrophobic films [5]. Frictional wear has been observed in operating devices under a variety of conditions [7-9]. Other researchers have successfully employed atomic force microscopy (AFM) to measure friction and wear [11]. While very useful, friction studies using AFM are limited to single asperity contact, which can be difficult to extrapolate to multicontact behavior of real surfaces.

A hinged pad test structure for static and sliding friction measurement in MEMS has been developed and manufactured [4] using Sandia National Laboratories' four layer polysilicon surface micromachining SUMMiT process [12]. The device allows friction measurement over a large pressure (10 $\mathrm{kPa}$ to $25 \mathrm{MPa}$ ) range. The small size may allow this new device to serve as 


\section{DISCLAIMER}

This report was prepared as an account of work sponsored by an agency of the United States Government. Neither the United States Government nor any agency thereof, nor any of their employees, make any warranty, express or implied, or assumes any legal liability or responsibility for the accuracy, completeness, or usefulness of any information, apparatus, product, or process disclosed, or represents that its use would not infringe privately owned rights. Reference herein to any specific commercial product, process, or service by trade name, trademark, manufacturer, or otherwise does not necessarily constitute or imply its endorsement, recommendation, or favoring by the United. States Government or any agency thereof. The views and opinions of authors expressed herein do not necessarily state or reflect those of the United States Government or any agency thereof. 


\section{DISCLAIMER}

Portions of this document may be illegible in electronic image products. Images are produced from the best available original document. 
an in-situ process monitors. However, the mechanics analysis for this device is relatively complex.

Preliminary testing of the device resulted in static coefficients of friction, $\mu_{s}$, of about 7 between polysilicon surfaces with a native oxide [4]. Based on those results, we implemented a number of design improvements. In this study, we validated the improved design, and applied it to characterize frictional properties of a silane coupling agent (PFTS, $\mathrm{C}_{8} \mathrm{~F}_{17} \mathrm{C}_{2} \mathrm{H}_{4} \mathrm{SiCl}_{3}$ ) coating as a function of normal pressure, and wear. The results from coated friction devices were compared to uncoated devices dried using the super critical $\mathrm{CO}_{2}\left(\mathrm{SCCO}_{2}\right)$ drying process [13].

\section{DEVICE DESIGN}

The design and modeling of the friction device have been previously described in ref. [4]. The friction device is essentially a cantilever beam of length $L$ with a friction pad structure attached to its free end via a torsional hinge. By bending the cantilever out-of-plane, a very high driving force to induce slip of the friction pad is achieved. The distributed normal force, $F_{\mathrm{N}}$ in Fig. 1(a), is applied to the friction pads electrostatically. The driver beam is pulled down towards the substrate by electrostatic loading, denoted as

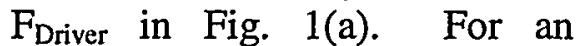
inextensible beam, the out of plane electrostatic forces applied

(a)

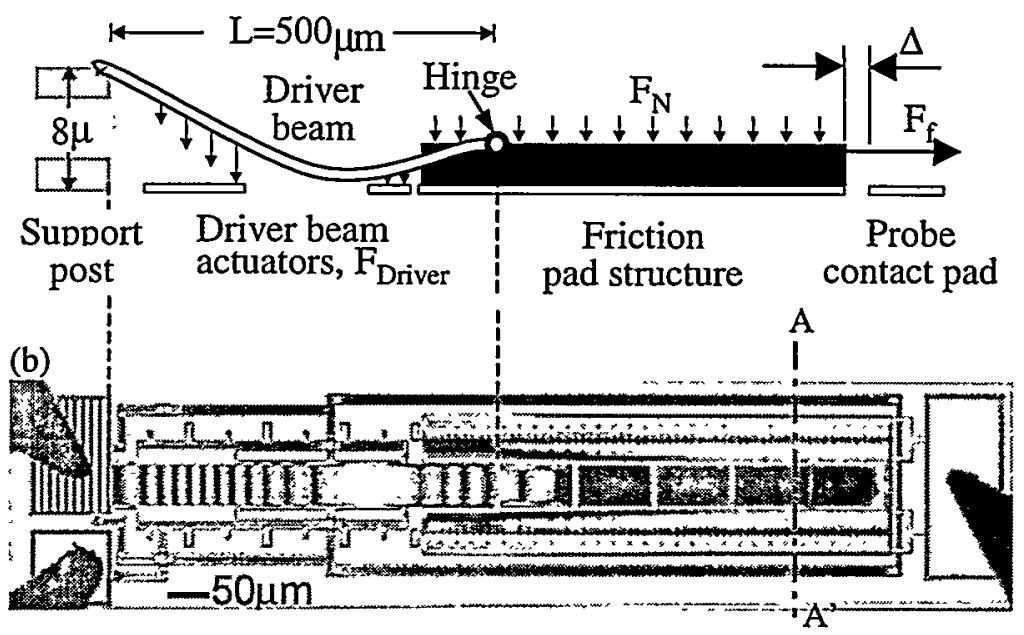

Fig. 1: (a) Schematic cross-section of the friction device. The normal force, $F_{N}$, is applied electrostatically, as is the driver beam actuation force, $F_{D r i v e r}$. (b) Plan-view interferogram of the friction device with $25 \mathrm{~V}$ applied to the friction pads and $110 \mathrm{~V}$ applied to the driver beam. The light and dark bands on the driver beam are interference fringes used to quantify the out-of-plane beam shape.

to the driver beam induce in-plane slip of the friction pad $\Delta$, given to first order by $\Delta=2 \delta^{2} / L$ where $\delta$ is the amplitude of beam deflection at its center. The first design improvement has been to increase $\delta$ from $\sim 2.1$ to $\sim 2.7 \mu \mathrm{m}$, by employing the principle of leverage bending [14]. This increases the maximum value of $\Delta$ from 18 to $30 \mathrm{~nm}$. While this remains a small slip device, this frictional displacement is now sufficient to allow multi-point sliding contact of the polysilicon surfaces. Frictional force, $\mathrm{F}_{\mathrm{f}}$, effectively stiffens the driver beam, reducing the maximum driver beam deflection for a given $F_{\text {Driver }}$. An interferometric microscope is used to quantify the deflected shape of the driver beam to $\mathrm{nm}$ scale accuracy. Because the shape of the deflected beam is very sensitive to any axial stiffening, the frictional force can be determined from the beam shape using finite element modeling, or an approximation method presented later in this paper. Fig. 1(b) shows a plan view of the friction device under interferometric conditions. Each interference fringe in Fig. 1(b) corresponds to an out of plane deflection of $\lambda / 2=274 \mathrm{~nm}$ for the green light used in our interferometer.

Fig. 2 shows a cross sectional schematic of the friction pad structure through section AA' of Fig. 1(b) before sacrificial oxide removal. Four levels of polysilicon (poly) designated as P0, $\mathrm{P} 1, \mathrm{P} 2$, and $\mathrm{P} 3$ are used to form the structure. Sacrificial oxide layers are designated as SO1, $\mathrm{SO} 2$, and $\mathrm{SO}$. The friction pad normal force, $\mathrm{F}_{\mathrm{N}}$, is achieved via electrostatic actuation between the P3 wings and the P1 actuation surfaces of Fig. 2. Note that because the gap between the 
friction pad and P0 is smaller than the gap between the wings and P1, the friction pad acts as a stop. This allows large voltages (applied between the grounded wings and the P1 pads) and hence large normal forces to be applied to the friction pad. The second design improvement is a more stable friction pad construction for stability against tipping under electrostatic normal loads up to $200 \mathrm{~V}(4 \mathrm{mN})$. The normal force applied to the friction pad is given by simple electrostatics,

$$
F_{N}=\varepsilon_{o} A_{N} V_{N}^{2} / 2 g_{N}^{2}
$$

where $\varepsilon_{o}$ is the permittivity of air, $A_{N}$ is the normal actuation surface area $\left(50,000 \mu \mathrm{m}^{2}\right), \mathrm{V}_{\mathrm{N}}$ is the applied voltage, and $g_{N}$ is the actuation gap $(3 \mu \mathrm{m}-1.8 \mu \mathrm{m}=1.2 \mu \mathrm{m})$ between the electrostatic wings and the P1 actuation surfaces after the friction pad structure has been pulled into contact with P0. An advantage of the interferometry is it allows us to determine the degree to which normal pressure is constant over the length of the friction pad [4]. Note in Fig. 1(b) that the friction pad/wing structure is flexing inward slightly, as indicated by the fringes parallel to the long dimension. This is due to the downward force exerted by the driver beam at the hinge and indicates the friction pad pressure is less uniform than we would like. This problem will be addressed in the next design. The driver beam actuation force is also determined by electrostatics, but now the varying actuation gap along the length of the beam must be considered. Once the normal force and the frictional force have been found, $\mu$ is calculated by the classical

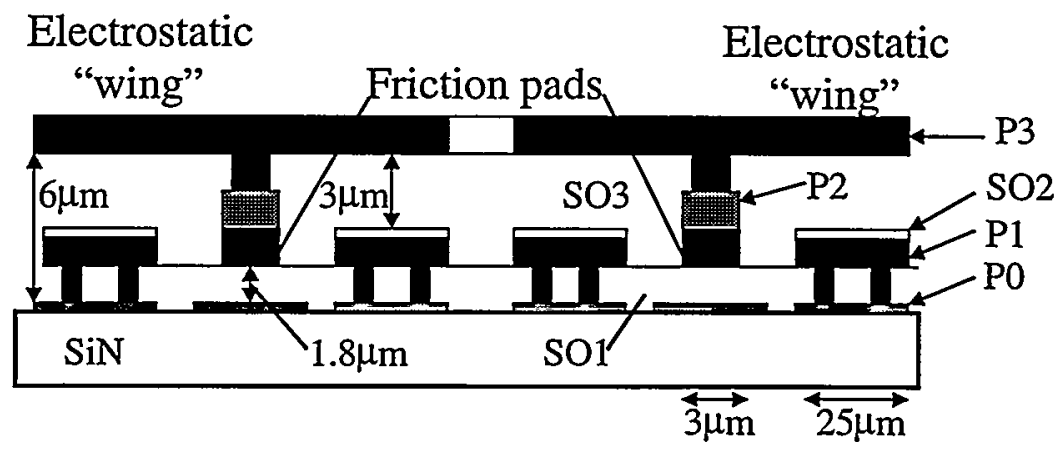

Fig. 2: Cross section AA' in Fig. 1b. Note the dual friction pads for stability against tipping. P-polysilicon SO-sacrificial oxide friction equation, $\mathrm{F}_{\mathrm{f}}=\mu \mathrm{F}_{\mathrm{N}}$.

\section{EXPERIMENTAL APPROACH AND RESULTS}

The structures are encased in sacrificial oxide until ready for use, at which point the devices are released in an $\mathrm{HF}$ bath that dissolves the $\mathrm{SiO}_{2}$ encapsulation. The drying stage following the release etch has proven to be a critical step because capillary forces readily pull device structural members into permanent contact with the substrate and/or other device structures [1,2]. Following rinsing of the samples, the devices are placed in a chamber containing $\mathrm{CO}_{2}$ above its critical point. In $\mathrm{SCCO}_{2}$ drying, the liquid solvents dissolve into the surrounding atmosphere of supercritical $\mathrm{CO}_{2}$, thus eliminating capillary forces between structural members [13]. Application of the PFTS coating was accomplished following the release etch by immersing the samples in a precursor solution containing PFTS molecules, similar to ref. [5]. Devices were stored in a nitrogen box until testing.

Friction testing was performed in a humidity-controlled chamber. To perform a friction test, the friction pad was first pulled into contact with the substrate with a voltage applied between the actuation wings and the actuation pads. Driver beam actuation was then steadily increased to induce slip of the friction pad, $\Delta=2 \delta^{2} / L$.

Two methods were used to acquire beam deflection data. In the first, the driver beam deflection profile was measured for a fixed driver beam actuation voltage. The amplitude of beam deflection is inversely related to the axial stiffening force $\left(F_{f}\right)$ under these conditions. The 
deflections could therefore be directly compared to get an idea of relative frictional force. In Fig. 3 , we see that the apparent normal pressure applied to the friction pad strongly affects driver beam deflections. This is strong evidence that axial force in the driver beams induces slip of the friction pad.

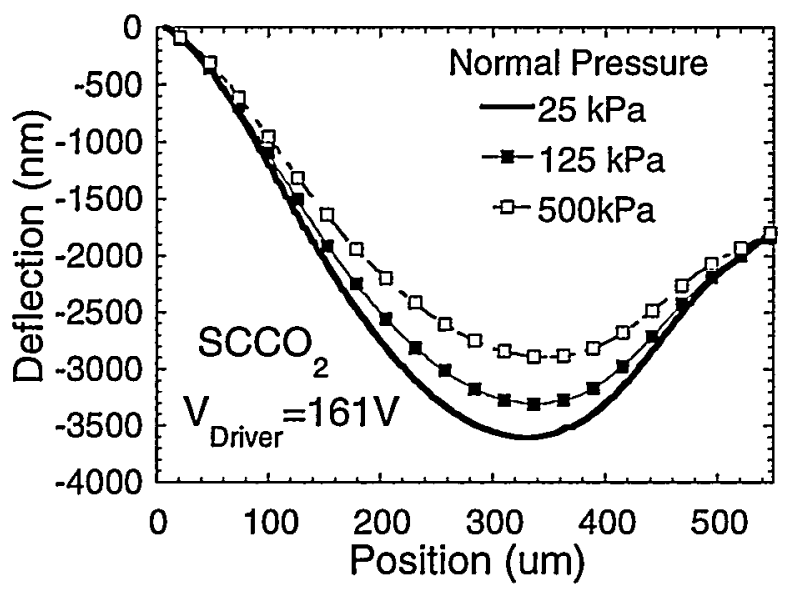

Fig.3: Beam profiles of an $\mathrm{SCCO}_{2}$ device measured at $V_{\text {Driver }}=161 \mathrm{~V}$ and three different normal pressures. Decreased driver displacement with increased normal pressure is indicative of increased $F_{f}$.

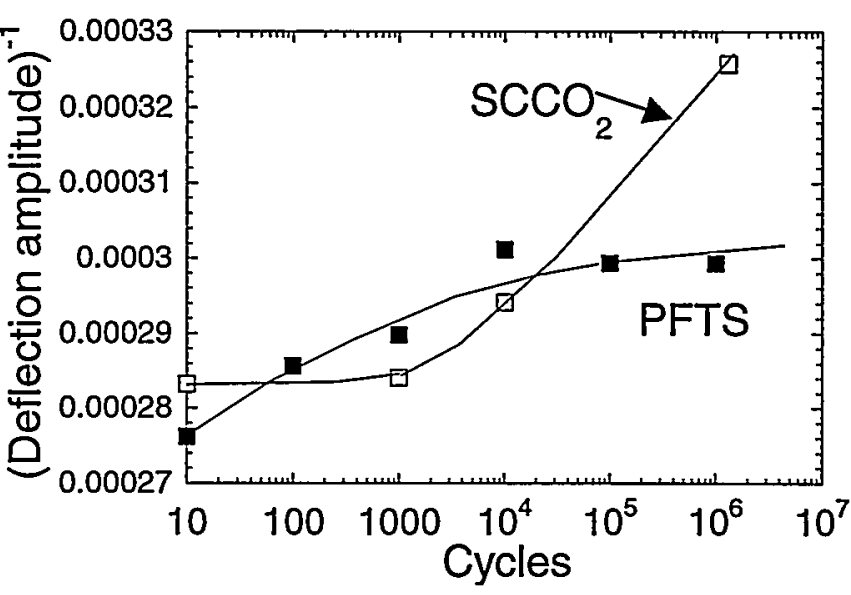

Fig.4: Increased friction with wear is observed for both surfaces. However, the trend for increased friction is significantly different for the two. surfaces.

Wear testing was performed by connecting the driver beam actuation probe to a waveform generator and actuating sinusoidally at $20 \mathrm{~Hz}$ with $\mathrm{V}_{\mathrm{N}}=25 \mathrm{~V}$ applied to the friction pads $\left(\mathrm{F}_{\mathrm{N}}=0.096 \mathrm{mN}, \mathrm{P}_{\mathrm{N}}=32 \mathrm{kPa}\right)$ and was periodically stopped after a number of cycles. Static measurements of friction were then carried out, again with $\mathrm{V}_{\mathrm{N}}=25 \mathrm{~V}$. Beam profiles were collected at the same driver actuation voltage. We see in Fig. 4 that the number of cycles also affects the slip of the friction pads.

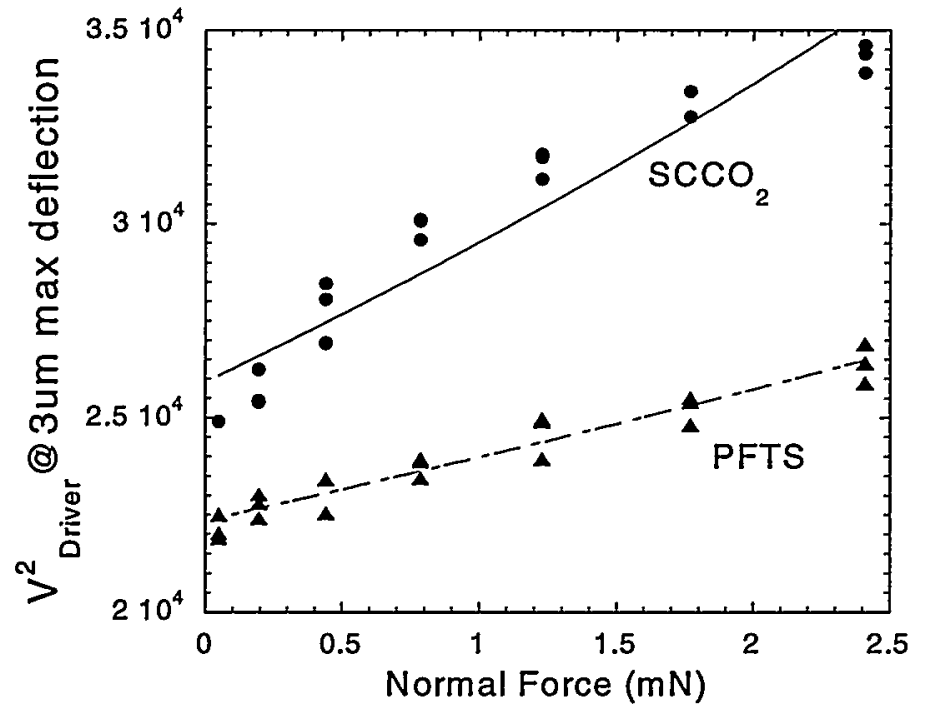

Fig. 5: Comparison of $\mathrm{SCCO}_{2}$ dried and PFTS coated devices. Fit lines from equation (2) match experimental data well, and show that PFTS coatings reduce $\mu$. Data taken at $40 \%$ relative humidity.
While the above method gives strong evidence for slip, finite element modeling is required to extract slip values and frictional forces. In the second method, as shown in Fig. 5, we plotted the required driver voltage to attain the same deflection amplitude $\delta=3 \mu \mathrm{m}$ as a function of normal force applied to the friction pad. A deflection of $\delta=3.0 \mu \mathrm{m}$ (measured from the point of maximum deflection to the same point on the beam when $V_{\text {Driver }}=0$ ) was chosen because for small voltage increments beyond that, the beam snaps into the substrate due to unstable electrostatic loading. For cases of high frictional force $\left(\mathrm{F}_{\mathrm{f}}\right.$ in Fig. 1(a)), the axial stiffness of the beam is higher than for cases of low friction. A higher out of plane beam actuation force $\left(\mathrm{F}_{\text {Driver }}\right)$ is therefore 
required to produce the same beam deflection of $3 \mu \mathrm{m}$. Measurement of $V_{\text {Driver }}^{2}$ to produce $\delta=3 \mu \mathrm{m}$ thus gives insight into the magnitude of the frictional force. We see in Fig. 5 that higher frictional force results from higher normal force applied to the friction pad, or from $\mathrm{SCCO}_{2}$ treatment rather than PFTS treatment.

\section{FIRST ORDER MODELING}

We apply an approximate first order method to infer the coefficient of friction for the two surface treatments. A straightforward approximation of $F_{\text {Driver }}$ can be made by recognizing that the beam shape and hence the average electrostatic actuation gap, gDriver, is approximately constant from test to test when $\delta$ is fixed at $3 \mu \mathrm{m}$. Since the actuation area is also constant $\left(A_{\text {Driver }}=14,000 \mu \mathrm{m}^{2}\right), F_{\text {Driver }}$ is a function of $V^{2}$ Driver alone. It can be shown using point-load beam mechanics [15] that the relationship between the out of plane force, $F_{\text {Driver, and the axial }}$ stiffening force (in this case $F_{f}$, which is equal to $\mu F_{N}$, forces in Newtons) to first order is approximately

$$
F_{\text {Driver }}=\frac{\varepsilon A_{\text {Driver }}}{2 g_{\text {Driver }}^{2}} * V_{\text {Driver }}^{2} \cong \alpha \frac{192 E I \delta}{L^{3}} 1.03 \exp \left(0.484 \mu F_{N}\right)
$$

where $I$ is the beams moment of inertia, $L$ is the length $(500 \mu \mathrm{m})$, and $\mathrm{E}=170 \mathrm{GPa}$ is the elastic modulus of polysilicon. Besides $V$ and $\mu$, all terms in equation 3 are constants for the given test conditions. The exponential term is a fit of the strain stiffening function determined using pointload beam mechanics and $\alpha$ accounts for the difference in point versus distributed loading. A plot of $V^{2}$ Driver against the normal force applied to the friction pads is therefore useful for semiquantitative friction comparison.

The plot presented in Fig. 5 is an application of the experimental method explained in the development of Eq. 2. Experimental data shows that PFTS coated devices have a lower coefficient of friction than $\mathrm{SCCO}_{2}$ dried devices by a factor of 2-3. Application of Eq. (2) and allowing $\alpha$ to vary between samples produces the fit lines shown and places the values of $\mu$ at 0.16 , for the PFTS coated device and 0.27 for the $\mathrm{SCCO}_{2}$ dried device. This value for $\mathrm{SCCO}_{2}$ dried devices is significantly lower than static coefficients reported elsewhere [10] while the coefficient for PFTS coated devices is in very good agreement with other researchers [5].

Fig. 3 shows three $\mathrm{SCCO}_{2}$ driver beam profiles at the same driver beam actuation voltage (161V), but with different normal forces applied to the friction pads. The trend of decreasing beam deflection with increased normal pressure is expected based on the inverse relationship between frictional force and beam displacement. However, a variation of the above semiquantitative analysis must be developed for beam profiles taken at constant driver voltage rather than constant deflection amplitude.

Preliminary wear results using the current friction device indicate an increase in friction with accumulated cycles for both $\mathrm{SCCO}_{2}$ dried and PFTS coated devices. Deflection data was collected in the same way as in Fig. 3, but has been presented differently in Fig. 4 to enable direct comparison between the two surface treatments. Fig. 4 shows the corresponding decrease in maximum beam deflection with accumulated wear cycles. In the case of $\mathrm{SCCO}_{2}$ dried devices, friction remains relatively unchanged up to about 1000 cycles, then exhibits a steady increase (decreased beam deflection) when the device is cycled beyond one million cycles. The PFTS coated sample represented in Fig. 5 shows a much different behavior. Friction increases quickly with the first 1000 cycles, but levels off after 10,000 cycles and remains basically 
unchanged in the range of 1 million cycles. The friction behavior was not determined beyond 1 million cycles. The difference between $\mathrm{SCCO}_{2}$ and PFTS surfaces may arise from differences in the way that wear debris is generated as the surfaces wear. SEM analysis of the worn devices should prove or disprove this possible mechanism.

\section{CONCLUSIONS}

A newly developed friction device has been improved and applied to measuring friction between polysilicon surfaces as a function of processing history, normal pressure, and wear. The device has allowed straightforward qualitative friction comparison. A semi-quantitative analysis routine has been developed, though further analysis is needed to improve its accuracy and to expand its applicability. True quantitative friction measurement will be possible when the FEM modeling routine has been perfected. PFTS monolayer coatings reduce friction between polysilicon surfaces when compared to $\mathrm{SCCO}_{2}$ dried surfaces. The values of $\mu$ are 0.16 for PFTS coated devices and 0.27 for $\mathrm{SCCO}_{2}$ dried surfaces. PFTS coatings also change the wear behavior of the surfaces. While $\mathrm{SCCO}_{2}$ dried surfaces degrade rapidly beyond 1000 cycles, PFTS coatings cause friction to reach a steady state condition after about 10,000 cycles. The mechanism for the difference is yet to be determined.

\section{ACKNOWLEDGEMENTS}

Sandia National Laboratories is a multiprogram laboratory operated by Sandia Corporation, a Lockheed-Martin company, for the United States Department of Energy under Contract DE-AC04-94AL85000. We thank the staff at the Microelectronics Development Laboratory at Sandia National Laboratories for fabricating and releasing devices. Also, to the NSF for partial financial support.

\section{REFERENCES}

1. M.P de Boer, J.A. Knapp, T.M. Mayer, T.A. Michalske. Proc. SPIE/EOS Conf. On Microsystems Metrology and Inspection, Munich, June 15, 3825 pp. 1-14, 1999.

2. C.H. Mastrangelo and C.H. Hsu. Proc. IEEE Solid-State Sensor \& Actuator Workshop, Hilton Head, SC, USA, pp. 208. 1992.

3. J.N. Israelachvili et al. J. Adhesion Sci. Technol., 8:11, pp. 1231-1249. 1994.

4. M.P deBoer, J.M. Redmond, T.A. Michalske. SPIE Proc. 3512. Santa Clara, CA. Sept. 1998.

5. U. Srinivasan, et al. IEEE Hilton Head '98, Hilton Head Island, SC, USA, 1998. pp.156-161.

6. S.L. Miller, J.J. Sniegowski, G. LaVigne, and P.J. McWhorter. Proc. SPIE Smart Electronics and MEMS, 2722, pp. 197-204. 1996.

7. M. Mehregany and S.D. Senturia. IEEE Trans. On Electron Devices, 39:5. 1992.

8. K. Deng, et al. J. Electrochem. Soc.,142:4. April 1995.

9. D.M.Tanner, J.A. Walraven, L. W. Irwin, et.al. IEEE Int. Reliability Phys. Symp. March 21-25 1999. pp. $189-197$

10. M.G. Lim et al. Proc. IEEE MEMS Workshop, Napa Valley, CA, USA, Feb. 1990, pp. 8288.

11. R.W. Carpick, M. Salmeron. Chem. Rev. 97:4, pp. 1163-1194. 1997.

12. J.J. Sniegowski and M.S. Rodgers. Tech.Dig. IEEE Int. Electron Devices Meeting, IEDM, Washington, D.C.Dec. 7-10, 1997, pp. 903-906.

13. C.W. Dyck, J.H. Smith, S.L: Miller, E.M Russick, C.L.J. Adkins. SPIE Micromachining and Microfabrication, October 1996.

14. E.S. Hung, and S.D. Senturia, IEEE Hilton Head '98, Hilton Head Island, SC, USA, June 1998, pp. 83-86.

15 . B.T. Crozier, to be published 